\title{
RAPD -PCR analysis of four coral reef fish species, genus cephalopholis (Family: serranidae) in the Red sea.
}

\author{
Abied, A.M. ${ }^{1}$; Abu El Regal, M.A. ${ }^{2}$ and Khalil, A.H ${ }^{1}$ \\ 1- Zoology Dept. Faculty of Science, Qena, South Valley University, Egypt. \\ 2- Marine Science Department, Faculty of Science, Port Said University, Egypt.
}

\section{ABSTRACT}

The genetic relationships between four species of groupers: Cephalopholis oligosticta, C. sexmaculata, C. hemistiktos and C. argus, common coral reef fish in the Red Sea of family Serranidae were studied by using Random Amplified Polymorphic DNA (RAPD) technique. Twenty random primers were used. Each primer was individually tested with the four fish species. Amplification products were resolved on agarose gel electrophoresis and visualized under UV light, then photographed. The number and size of amplified DNA fragments showed a wide range of variation. Tabulation and analysis of the data using the genetic similarity coefficient were carried out. The highest genetic similarity observed was between $C$. hemistiktos and $C$ argus and the lowest was between $C$. oligosticta and $C$. sexmaculata. Dendrogram analysis revealed three clusters: first, comprises $C$. hemistiktos and C. argus; second, contains $C$. oligosticta and (C. hemistiktos and $C$. argus); the third incompasses $C$. sexmaculata and (C. oligosticta, C. hemistiktos and C. argus).

Keywords: Cephalopholis, Serranidae, RAPD -PCR, Genetic Variation, Red sea

\section{INTRODUCTION}

Random amplified polymorphic DNA (RAPD) is a PCR- based molecular marker developed by Williams et al. (1990) which have been demonstrated to be useful not only for the study of population genetic variation but also for taxonomic identities, systematic relationships, parent- age identifications, identification of interspecific hybridization and introgressive hybridization (Imtiaz et al., 2011).

RAPD technique has several advantages and has been quite widely employed in fisheries studies. The method is simple, rapid and cheap, it has high polymorphism. Only a small amount of DNA is required, no need for molecular hybridization and most importantly no prior knowledge of the genetic make-up of the organism in question is required. The technique is based on PCR amplification of discrete regions of genome with short oligonucleotide primers of arbitrary sequence Okumus and Çiftci (2003).

Among the several available molecular markers, RAPD (randomly amplified polymorphic DNA) stands for a simple and cost-efficient assay to evaluate genetic variability, regardless any previous genomic information about the selected organism (Dinesh et al., 1993; Wasko et al., 2004b; Affonso and Galetti, 2007). RAPD is a highly useful technique for phylogenetic analysis among related individuals, the RAPD-PCR analysis has proven to be helpful in taxonomic studies (Sleem and Ali, 2008).

Several authors (Welsh and McClelland, 1990; Baradakci and Skibinski, 1994; Naish et al., 1995) have demonstrated that the RAPD PCR method is a powerful tool 
for the assessment of genetic markers that are capable of discriminating between species or subspecies in a wide range of organisms, including fishes.

Several nuclear DNA techniques have been available in accessing genetic variability in fish species and have been employed in aquaculture studies. On the other hand, the use of RAPD assay for genetic analysis of fishes has been fairly limited in comparison to published reports on microorganism, plant and insect species (Park and Moran, 1994; Mjolnerod et al., 1997; Norris et al., 1999 and El-Alfy et al., 2009).

Cephalopholis is the most common genus of Serranidae family found in the aquarium trade. Some species of the genus Cephalopholis feature have colorful bodies. Most Cephalopholis are Indo-Pacific (12 species), some Red Sea, western and eastern Atlantic, Oceania (mid- tropical Pacific) and one from the eastern Pacific. Mostly are found in shallows to a few hundred feets in areas with lots of hiding opportunities. The fishes in this genus are robust, somewhat elongate marine predators that specialize in ambush tactics when hunting. The genus comprises 22 species (Heemstra and Randall, 1993; Fenner, 1996 and FAO, 2001).

In the present study, we applied the RAPD technique in revealing the genetic variation in four species of the genus Cephalopholis.

\section{MATERIAL AND METHODS}

Samples of Cephalopholis oligosticta, C. sexmaculata, C. hemistiktos and C. argus were collected from Hurghada by fishermen of the National Institute of Oceanography and Fisheries (Red Sea Branch). Fishes were dissected immediately after capture; liver, kidney, gills and gonads were isolated, bulked in 95\% ethanol and stored in a freezer until processed for RAPD technique.

\section{Extraction and Purification of Genomic DNA:}

DNA extraction using the Qiagen DNeasy (Qiagen Santa Clara, CA), that was performed following the manufacturer's instructions as follows:

1 - A volume of $400 \mu \mathrm{l}$ of buffer AP1 and $4 \mu \mathrm{l}$ of RNase A stock solution $(100 \mathrm{mg} / \mathrm{ml})$ were added to a maximum of $100 \mathrm{mg}$ of ground animal tissue and vortexed vigorously.

2- The mixture was incubated for $10 \mathrm{~min}$ at $65^{\circ} \mathrm{C}$, and mixed about 2-3 times during incubation by inverting tube.

3- Buffer AP2 130 $\mu$ l was added to the lysate, mixed and incubated for $5 \mathrm{~min}$ on ice.

4- The lysate was applied to the QIAshredder mini spin column, placed in a $2 \mathrm{ml}$ collection tube and centrifuged for 2 min at $14000 \mathrm{rpm}$.

5- Flow-through fraction from step 4 was transferred to a new tube without disturbing the cell-debris pellet.

6- 1.5 volumes of Buffer AP3/E was added to the cleared lysate and mixed by pipetting.

7- A volume of $650 \mu$ l of the mixture from step 6 , including any precipitate which may have formed, were applied to the DNeasy mini spin column sitting in a $2 \mathrm{ml}$ collection tube. Centrifuged for $1 \mathrm{~min}$ at $8000 \mathrm{rpm}$ and flow-through was discard.

8- Step 7 was repeated with remaining sample, the flow-through and collection tube were discard.

9- DNeasy mini spin column was placed in a new $2 \mathrm{ml}$ collection tube, $500 \mu \mathrm{l}$ buffer AW was added to the DNeasy mini spin column and centrifuged for 1 min at $>8000 \mathrm{rpm}$ the flow-through was discard and the collection tube was reused in step 10. 
10- Buffer AW $500 \mu \mathrm{l}$ was added to the DNeasy mini spin column and centrifuged for 2 min at $14000 \mathrm{rpm}$ to dry the membrane.

11- The DNeasy mini spin column was transferred to a $1.5 \mathrm{ml}$ microcentrifuge tube and $100 \mu \mathrm{l}$ of buffer AE was pipeted directly onto the DNeasy membrane. The microcentrifuge was incubated for $5 \mathrm{~min}$ at room temperature $\left(15-25^{\circ} \mathrm{C}\right)$ and then centrifuged for $1 \mathrm{~min}$ at $>8000 \mathrm{rpm}$ to elute.

12- Step 11was repeated once.

\section{Estimation of DNA Concentration:}

DNA concentration was determined by diluting the DNA 1:5 in dist. $\mathrm{H}_{2} \mathrm{O}$. The DNA samples were electrophoresed in 1\% agarose gel against $10 \mathrm{ng}$ of a DNA size marker. This marker covers a range of concentration between $95 \mathrm{ng}$ and $11 \mathrm{ng}$. Thus, estimation of the DNA concentration in a given sample was achieved by comparing the degree of fluorescence of the unknown DNA band with the different bands in the DNA size marker.

\section{RAPD-PCR protocol:}

A set of twenty random 10-mer primers as shown in Table (1) were used in the detection of polymorphism. The amplification reaction was carried out in $25 \mu 1$ reaction volume containing $1 \mathrm{X}$ PCR buffer, $1.5 \mathrm{mM} \mathrm{MgCl} 2,0.2 \mathrm{mM}$ dNTPs, $1 \mu \mathrm{M}$ primer, $1 \mathrm{U}$ Taq DNA polymerase and $25 \mathrm{ng}$ templates DNA. PCR amplification was performed in a Perkin-Elmer/GeneAmp® PCR System 9700 (PE Applied Biosystems) programmed to fulfill 40 cycles after an initial denaturation cycle for 5 min at $94^{\circ} \mathrm{C}$. Each cycle consisted of a denaturation step at $94^{\circ} \mathrm{C}$ for $1 \mathrm{~min}$, an annealing step at $36^{\circ} \mathrm{C}$ for $1 \mathrm{~min}$, and an elongation step at $72^{\circ} \mathrm{C}$ for $1.5 \mathrm{~min}$. The primer extension segment was extended to $7 \mathrm{~min}$ at $72^{\circ} \mathrm{C}$ in the final cycle. The amplification products were resolved by electrophoresis in a 1,5\% agarose gel containing ethidium bromide $(0.5 \mathrm{ug} / \mathrm{ml})$ in $1 \mathrm{X}$ TBE buffer at 95 volts. PCR products were visualized on UV light and photographed using a Polaroid camera. Amplified products were visually examined and the presence or absence of each size class was scored as 1 or 0 , respectively.

Table 1: Primers and primer sequences used for amplification and sequencing, where A: Adenine, T: Thymine, G: Guanine and C: Cytosine

\begin{tabular}{|c|c|c|c|c|}
\hline No. & Primer code & Nucleotide sequence (5 ${ }^{`}$ to $3^{\prime}$ ) & Nucleotide length & GC\% \\
\hline 1 & OPA-04 & AATCGGGCTG & $10-\mathrm{mer}$ & 60 \\
\hline 2 & OPA-06 & GGTCCCTGAC & $10-\mathrm{mer}$ & 70 \\
\hline 3 & OPA-11 & CAATCGCCGT & $10-\mathrm{mer}$ & 60 \\
\hline 4 & OPA-17 & GACCGCTTGT & $10-\mathrm{mer}$ & 60 \\
\hline 5 & OPB-14 & TCCGCTCTGG & $10-\mathrm{mer}$ & 70 \\
\hline 6 & OPD-01 & ACCGCGAAGG & $10-\mathrm{mer}$ & 70 \\
\hline 7 & OPD-14 & CTTCCCCAAG & $10-\mathrm{mer}$ & 60 \\
\hline 8 & OPE-05 & TCAGGGAGGT & $10-\mathrm{mer}$ & 60 \\
\hline 9 & OPG-03 & GAGCCCTCCA & $10-\mathrm{mer}$ & 70 \\
\hline 10 & OPG-07 & GAACCTGCGG & $10-\mathrm{mer}$ & 70 \\
\hline 11 & OPG-13 & CTCTCCGCCA & $10-\mathrm{mer}$ & 70 \\
\hline 12 & OPG-19 & GTCAGGGCAA & $10-\mathrm{mer}$ & 60 \\
\hline 13 & OPH-13 & GACGCCACAC & $10-\mathrm{mer}$ & 70 \\
\hline 14 & OPM-11 & GTCCACTGTG & $10-\mathrm{mer}$ & 60 \\
\hline 15 & OPM-12 & GGGACGTTGG & $10-\mathrm{mer}$ & 70 \\
\hline 16 & OPO-09 & TCCCACGCAA & $10-\mathrm{mer}$ & 60 \\
\hline 17 & OPZ-01 & TCTGTGCCAC & $10-\mathrm{mer}$ & 60 \\
\hline 18 & OPZ-04 & AGGCTGTGCT & $10-\mathrm{mer}$ & 60 \\
\hline 19 & OPZ-13 & GACTAAGCCC & $10-\mathrm{mer}$ & 60 \\
\hline 20 & OPZ-19 & GTGCGAGCAA & $10-\mathrm{mer}$ & 60 \\
\hline
\end{tabular}




\section{Data Analysis:}

The banding patterns generated by RAPD-PCR marker analyses were compared to determine the genetic relatedness of the four sample fish accessions. Clear and distinct amplification products were scored as ' 1 ' for presence and ' 0 ' for absence of bands. Bands of the same mobility were scored as identical.

The genetic similarity coefficient (GS) between two genotypes was estimated according to Dice coefficient (Sneath and Sokal, 1973).

$$
\mathbf{G S}_{\mathrm{ij}}=\mathbf{2 a} /(\mathbf{2 a}+\mathbf{b}+\mathbf{c})
$$

Where $\mathbf{G S}_{\mathbf{i j}}$ is the measure of genetic similarity between individuals $i$ and $j$, $\mathbf{a}$ is the number of bands shared by $i$ and $j$, $\mathbf{b}$ is the number of bands present in $i$ and absent in $j$, and $\mathbf{c}$ is the number of bands present in $j$ and absent in $i$.

The similarity matrix was used in the cluster analysis. The cluster analysis was employed to organize the observed data into meaningful structures to develop taxonomies.

At the first step, when each accession represents its own cluster, the distances between these accessions are defined by the chosen distance measure (Dice coefficient). However, once several accessions have been linked together, the distance between two clusters is calculated as the average distance between all pairs of accessions in the two different clusters. This method is called Unweighted Pair Group Method using Arithmetic Average (UPGMA) (Sneath and Sokal, 1973).

\section{RESULTS AND DISCUSSION}

Twenty single 10-mer primers as shown in Table (1) were used in the present study to determine the genetic differences among four species of genus Cephalopholis (C. oligosticta, C. sexmaculata, C. hemistiktos and C. argus). The $\mathrm{G}+\mathrm{C}$ contents of the twenty primers were between $60 \% \& 70 \%$. All primers were successfully amplified on the genomic DNA extracted from all studied fish species.

The results of RAPD analysis obtained by primer OPA-04 reacted with genomic DNA of the samples (Cephalopholis oligosticta, C. sexmaculata, C. hemistiktos and C. argus) and gave 12 bands (fragments) ranged in size between 160 to 680 as shown in Table (2) and Fig. (1) while it (OPA-04) generated 16 fragments in Oreochromis niloticus, O. aureus and Tilapia zillii from family Cichilidae (El-Alfy et al., 2009), primer OPA-06 generated 10 DNA bands from 110 to 520 bp (Table 3 \& Fig 2), OPA-11 12 fragments between 120 and 720 bp. (Table 4 \& Fig 3), OPA-17 14 DNA bands from 150 to $500 \mathrm{bp}$ (Table 5 \& Fig. 4) and primer OPB-14 generated 9 fragments ranged in size between 200 and 750 bp (Table $6 \&$ Fig. 5). 
Table 2: Survey of RAPD markers using Primer (OPA-04) in bulked samples of, Cephalopholis speciemens. Fig (30): Agarose-gel electrophoresis of RAPD products generated with Primer OPO-09 with the four species

\begin{tabular}{|c|c|c|c|c|c|}
\hline Band No. & RAPD Marker bp & $\mathbf{1}$ & $\mathbf{2}$ & $\mathbf{3}$ & $\mathbf{4}$ \\
\hline $\mathbf{1}$ & $\mathbf{1 6 0}$ & 1 & 0 & 1 & 1 \\
\hline $\mathbf{2}$ & $\mathbf{1 8 0}$ & 0 & 1 & 1 & 1 \\
\hline $\mathbf{3}$ & $\mathbf{2 1 0}$ & 1 & 1 & 1 & 0 \\
\hline $\mathbf{4}$ & $\mathbf{2 2 0}$ & 0 & 0 & 1 & 1 \\
\hline $\mathbf{5}$ & $\mathbf{2 3 0}$ & 0 & 0 & 0 & 1 \\
\hline $\mathbf{6}$ & $\mathbf{2 5 0}$ & 1 & 0 & 1 & 1 \\
\hline $\mathbf{7}$ & $\mathbf{2 8 0}$ & 1 & 1 & 1 & 1 \\
\hline $\mathbf{8}$ & $\mathbf{3 0 0}$ & 0 & 0 & 1 & 1 \\
\hline $\mathbf{9}$ & $\mathbf{3 5 0}$ & 0 & 1 & 0 & 0 \\
\hline $\mathbf{1 0}$ & $\mathbf{5 1 0}$ & 0 & 1 & 1 & 1 \\
\hline $\mathbf{1 1}$ & $\mathbf{6 2 0}$ & 0 & 0 & 1 & 1 \\
\hline 12 & $\mathbf{6 8 0}$ & 0 & 0 & 1 & 0 \\
\hline
\end{tabular}

Table 3: Survey of RAPD markers using Primer (OPA-06) in bulked samples of, Cephalopholis speciemens.

\begin{tabular}{|c|c|c|c|c|c|}
\hline Band No. & RAPD Marker bp & $\mathbf{1}$ & $\mathbf{2}$ & $\mathbf{3}$ & $\mathbf{4}$ \\
\hline $\mathbf{1}$ & $\mathbf{1 1 0}$ & 1 & 0 & 1 & 1 \\
\hline $\mathbf{2}$ & $\mathbf{1 3 0}$ & 0 & 1 & 0 & 0 \\
\hline $\mathbf{3}$ & $\mathbf{1 5 0}$ & 1 & 1 & 1 & 0 \\
\hline $\mathbf{4}$ & $\mathbf{1 7 0}$ & 1 & 0 & 1 & 1 \\
\hline $\mathbf{5}$ & $\mathbf{1 9 0}$ & 1 & 0 & 1 & 1 \\
\hline $\mathbf{6}$ & $\mathbf{2 1 0}$ & 1 & 1 & 1 & 1 \\
\hline $\mathbf{7}$ & $\mathbf{2 3 0}$ & 1 & 0 & 1 & 1 \\
\hline $\mathbf{8}$ & $\mathbf{2 7 0}$ & 1 & 0 & 0 & 0 \\
\hline $\mathbf{9}$ & $\mathbf{3 1 0}$ & 1 & 0 & 1 & 0 \\
\hline $\mathbf{1 0}$ & $\mathbf{5 2 0}$ & 0 & 1 & 0 & 0 \\
\hline
\end{tabular}

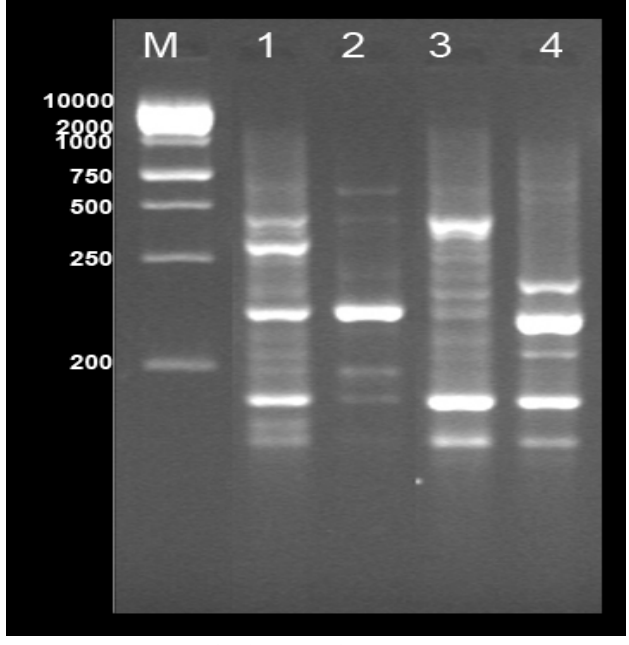

Fig. 1: Agarose-gel electrophoresis of RAPD products generated with Primer OPA-04 with the four species.

Where 1-Cephalopholis oligosticta, 2Cephalopholis sexmaculata, 3-Cephalopholis hemistiktos and 4-Cephalopholis argus.

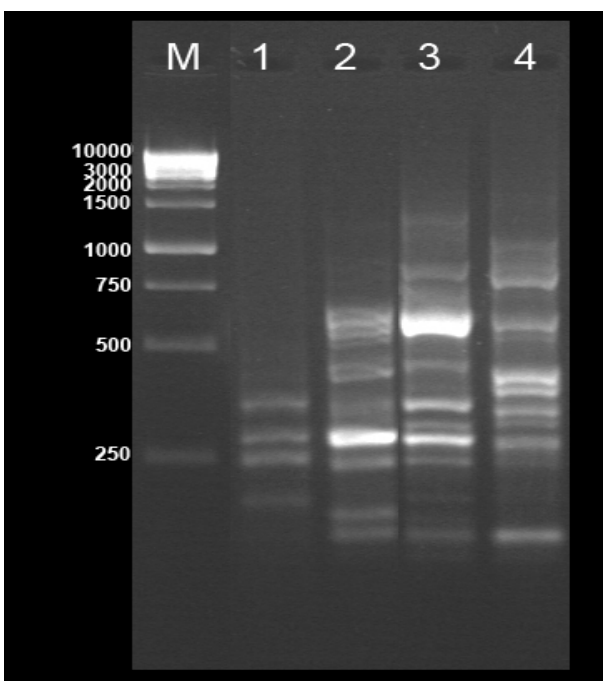

Fig. 2: Agarose-gel electrophoresis of RAPD products generated with Primer OPA-06 with the four species. 
Table 4: Survey of RAPD markers using Primer (OPA-11) in bulked samples of, Cephalopholis speciemens.

\begin{tabular}{|c|c|c|c|c|c|}
\hline Band No. & RAPD Marker bp & $\mathbf{1}$ & $\mathbf{2}$ & $\mathbf{3}$ & $\mathbf{4}$ \\
\hline $\mathbf{1}$ & $\mathbf{1 2 0}$ & 0 & 1 & 1 & 1 \\
\hline $\mathbf{2}$ & $\mathbf{1 5 0}$ & 1 & 1 & 1 & 1 \\
\hline $\mathbf{3}$ & $\mathbf{1 7 0}$ & 1 & 1 & 1 & 1 \\
\hline $\mathbf{4}$ & $\mathbf{1 8 0}$ & 0 & 0 & 1 & 1 \\
\hline $\mathbf{5}$ & $\mathbf{2 0 0}$ & 1 & 1 & 1 & 1 \\
\hline $\mathbf{6}$ & $\mathbf{2 1 0}$ & 1 & 1 & 1 & 1 \\
\hline $\mathbf{7}$ & $\mathbf{2 2 0}$ & 0 & 0 & 0 & 1 \\
\hline $\mathbf{8}$ & $\mathbf{2 4 0}$ & 0 & 1 & 1 & 1 \\
\hline $\mathbf{9}$ & $\mathbf{2 7 0}$ & 0 & 1 & 0 & 1 \\
\hline $\mathbf{1 0}$ & $\mathbf{3 1 0}$ & 0 & 1 & 1 & 1 \\
\hline $\mathbf{1 1}$ & $\mathbf{5 2 0}$ & 0 & 0 & 1 & 1 \\
\hline $\mathbf{1 2}$ & $\mathbf{7 2 0}$ & 0 & 0 & 1 & 0 \\
\hline
\end{tabular}

Table 5: Survey of RAPD markers using Primer (OPA17) in bulked samples of the four species.

\begin{tabular}{|c|c|c|c|c|c|}
\hline Band No. & RAPD Marker bp & $\mathbf{1}$ & $\mathbf{2}$ & $\mathbf{3}$ & $\mathbf{4}$ \\
\hline $\mathbf{1}$ & $\mathbf{1 5 0}$ & 1 & 0 & 0 & 0 \\
\hline $\mathbf{2}$ & $\mathbf{1 6 0}$ & 1 & 1 & 1 & 1 \\
\hline $\mathbf{3}$ & $\mathbf{1 8 0}$ & 1 & 1 & 1 & 1 \\
\hline $\mathbf{4}$ & $\mathbf{1 9 0}$ & 1 & 0 & 1 & 1 \\
\hline $\mathbf{5}$ & $\mathbf{2 0 0}$ & 1 & 1 & 1 & 1 \\
\hline $\mathbf{6}$ & $\mathbf{2 1 0}$ & 1 & 1 & 1 & 1 \\
\hline $\mathbf{7}$ & $\mathbf{2 2 0}$ & 1 & 1 & 0 & 0 \\
\hline $\mathbf{8}$ & $\mathbf{2 3 0}$ & 0 & 1 & 1 & 1 \\
\hline $\mathbf{9}$ & $\mathbf{2 4 0}$ & 0 & 0 & 1 & 1 \\
\hline $\mathbf{1 0}$ & $\mathbf{2 5 0}$ & 1 & 0 & 0 & 0 \\
\hline $\mathbf{1 1}$ & $\mathbf{2 7 0}$ & 1 & 1 & 1 & 1 \\
\hline $\mathbf{1 2}$ & $\mathbf{3 0 0}$ & 1 & 0 & 0 & 1 \\
\hline $\mathbf{1 3}$ & $\mathbf{4 2 0}$ & 1 & 1 & 0 & 1 \\
\hline $\mathbf{1 4}$ & $\mathbf{5 0 0}$ & 1 & 1 & 1 & 1 \\
\hline
\end{tabular}

Table 6: Survey of RAPD markers using Primer (OPB-14) in bulked samples of the four species.

\begin{tabular}{|c|c|c|c|c|c|}
\hline Band No. & RAPD Marker bp & $\mathbf{1}$ & $\mathbf{2}$ & $\mathbf{3}$ & $\mathbf{4}$ \\
\hline $\mathbf{1}$ & $\mathbf{2 0 0}$ & 0 & 1 & 1 & 1 \\
\hline $\mathbf{2}$ & $\mathbf{2 5 0}$ & 0 & 1 & 1 & 1 \\
\hline $\mathbf{3}$ & $\mathbf{2 6 0}$ & 0 & 0 & 0 & 1 \\
\hline $\mathbf{4}$ & $\mathbf{2 8 0}$ & 0 & 1 & 0 & 1 \\
\hline $\mathbf{5}$ & $\mathbf{3 5 0}$ & 0 & 1 & 0 & 1 \\
\hline $\mathbf{6}$ & $\mathbf{4 5 0}$ & 0 & 1 & 0 & 0 \\
\hline $\mathbf{7}$ & $\mathbf{5 8 0}$ & 1 & 1 & 1 & 1 \\
\hline $\mathbf{8}$ & $\mathbf{6 5 0}$ & 1 & 0 & 0 & 1 \\
\hline $\mathbf{9}$ & $\mathbf{7 5 0}$ & 0 & 1 & 0 & 0 \\
\hline
\end{tabular}

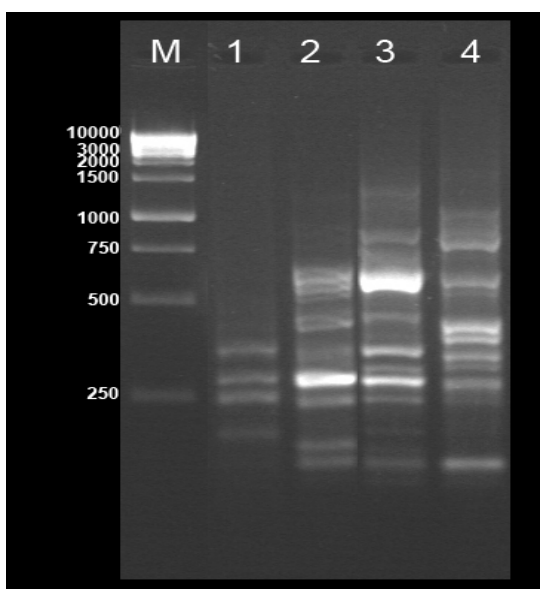

Fig. 3: Agarose-gel electrophoresis of RAPD products generated with Primer OPA-11 with the four species.

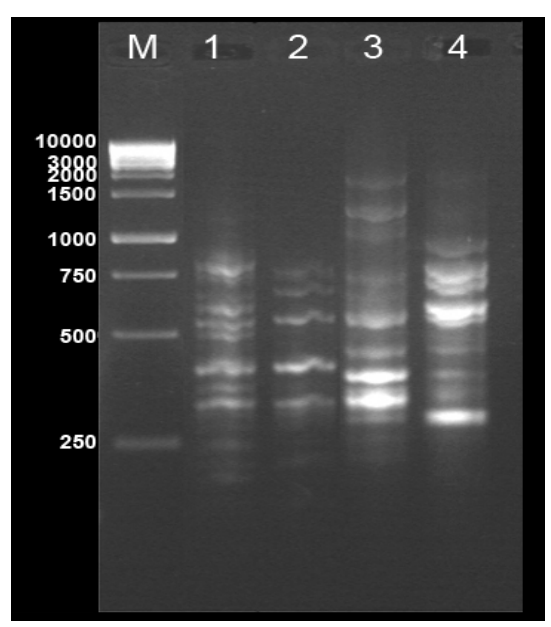

Fig. 4: Agarose-gel electrophoresis of RAPD products generated with Primer OPA-17 with the four species.

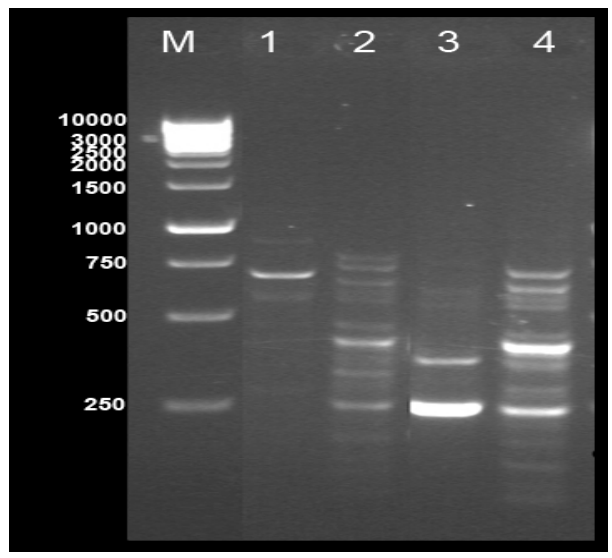

Fig. 5: Agarose-gel electrophoresis of RAPD products generated with Primer OPB-14 with the four species. 
The primer OPD-01 reacted with genomic DNA of the four species generated 10 fragments ranged in size between 230 and 800 bp (Table 7 \& Fig. 6), while it generated 17 bands all polymorphic bands and fragments size range 1356-135bp in Plectropomus maculates, Plectropomus leopardus and Plectropomus areolatus from family Serranidae (Saad et al., 2012), primer OPD-14 generated 9 DNA bands between 270 and 900 bp (Table 8 \& Fig. 7) (89\%) of these fragments ( 8 fragments) were polymorphic between the four species, primer OPE-05 gave 6 bands between 300 to 1000 bp (Table $9 \&$ Fig. 8), OPG-03 generated 8 DNA bands from 150 to 750 bp. (Table 10 \& Fig. 9) and primer OPG-07 generated 14 DNA bands ranged in size from 150 to $1200 \mathrm{bp}$ (Table $11 \&$ Fig. 10).

Table 7: Survey of RAPD markers using Primer (OPD- 01) in bulked samples of the four species.

\begin{tabular}{|c|c|c|c|c|c|}
\hline Band No. & RAPD Marker bp & $\mathbf{1}$ & $\mathbf{2}$ & $\mathbf{3}$ & $\mathbf{4}$ \\
\hline $\mathbf{1}$ & $\mathbf{2 3 0}$ & 0 & 0 & 1 & 1 \\
\hline $\mathbf{2}$ & $\mathbf{2 7 0}$ & 1 & 0 & 0 & 1 \\
\hline $\mathbf{3}$ & $\mathbf{3 2 0}$ & 1 & 0 & 0 & 1 \\
\hline $\mathbf{4}$ & $\mathbf{3 7 0}$ & 1 & 0 & 0 & 0 \\
\hline $\mathbf{5}$ & $\mathbf{4 6 0}$ & 1 & 0 & 0 & 0 \\
\hline $\mathbf{6}$ & $\mathbf{5 3 0}$ & 0 & 0 & 0 & 1 \\
\hline $\mathbf{7}$ & $\mathbf{5 5 0}$ & 1 & 1 & 0 & 1 \\
\hline $\mathbf{8}$ & $\mathbf{6 8 0}$ & 1 & 0 & 0 & 1 \\
\hline $\mathbf{9}$ & $\mathbf{7 0 0}$ & 1 & 0 & 0 & 0 \\
\hline $\mathbf{1 0}$ & $\mathbf{8 0 0}$ & 1 & 0 & 0 & 0 \\
\hline
\end{tabular}

Table 8: Survey of RAPD markers using Primer (OPD- 14) in bulked samples of the four species.

\begin{tabular}{|c|c|c|c|c|c|}
\hline Band No. & RAPD Marker bp & $\mathbf{1}$ & $\mathbf{2}$ & $\mathbf{3}$ & $\mathbf{4}$ \\
\hline $\mathbf{1}$ & $\mathbf{2 7 0}$ & 1 & 0 & 0 & 1 \\
\hline $\mathbf{2}$ & $\mathbf{3 0 0}$ & 1 & 0 & 1 & 1 \\
\hline $\mathbf{3}$ & $\mathbf{4 0 0}$ & 1 & 1 & 1 & 1 \\
\hline $\mathbf{4}$ & $\mathbf{5 0 0}$ & 1 & 0 & 0 & 1 \\
\hline $\mathbf{5}$ & $\mathbf{5 6 0}$ & 1 & 0 & 1 & 1 \\
\hline $\mathbf{6}$ & $\mathbf{6 5 0}$ & 1 & 0 & 0 & 1 \\
\hline $\mathbf{7}$ & $\mathbf{7 5 0}$ & 0 & 0 & 1 & 0 \\
\hline $\mathbf{8}$ & $\mathbf{8 5 0}$ & 1 & 0 & 1 & 1 \\
\hline $\mathbf{9}$ & $\mathbf{9 0 0}$ & 1 & 0 & 0 & 1 \\
\hline
\end{tabular}

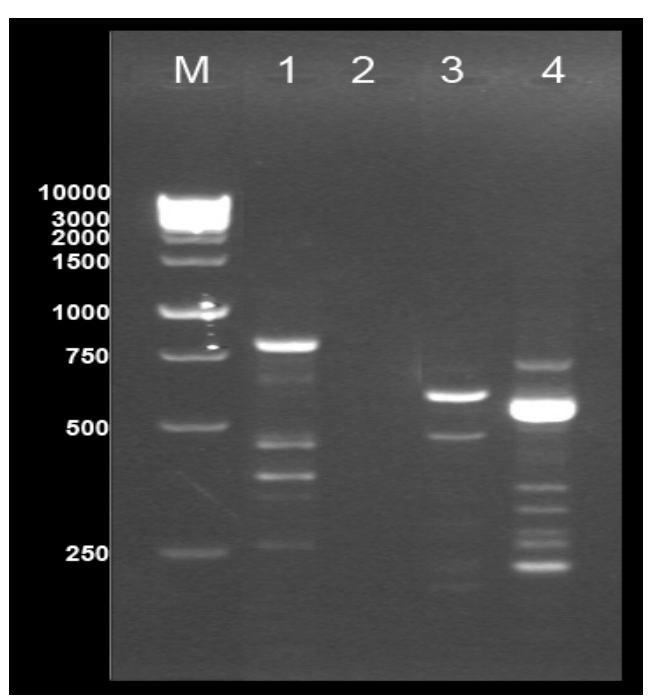

Fig. 6: Agarose-gel electrophoresis of RAPD products generated with Primer OPD-01 with the four species.

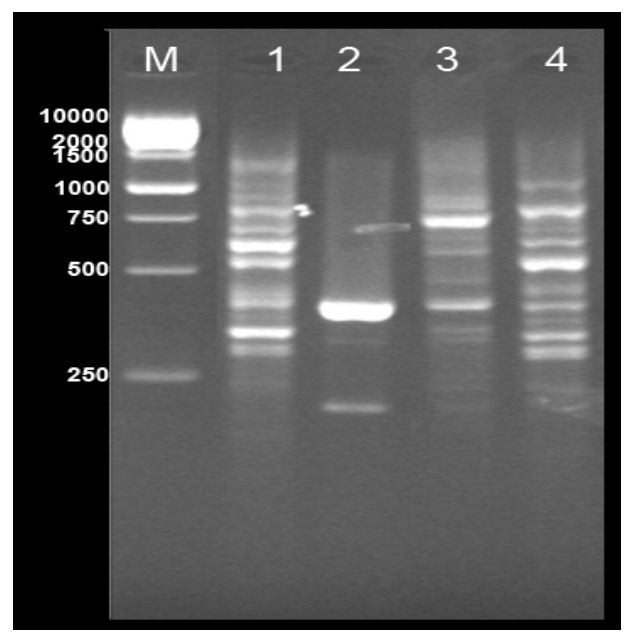

Fig. 7: Agarose-gel electrophoresis of RAPD products generated with Primer OPD-14 with the four species. 
Table 9: Survey of RAPD markers using Primer (OPE-05) in bulked samples of the four species.

\begin{tabular}{|c|c|c|c|c|c|}
\hline Band No. & RAPD Marker bp & $\mathbf{1}$ & $\mathbf{2}$ & $\mathbf{3}$ & $\mathbf{4}$ \\
\hline $\mathbf{1}$ & $\mathbf{3 0 0}$ & 1 & 0 & 1 & 0 \\
\hline $\mathbf{2}$ & $\mathbf{4 5 0}$ & 1 & 1 & 0 & 1 \\
\hline $\mathbf{3}$ & $\mathbf{5 0 0}$ & 1 & 1 & 0 & 0 \\
\hline $\mathbf{4}$ & $\mathbf{6 0 0}$ & 1 & 1 & 0 & 1 \\
\hline $\mathbf{5}$ & $\mathbf{8 0 0}$ & 1 & 1 & 0 & 1 \\
\hline $\mathbf{6}$ & $\mathbf{1 0 0 0}$ & 0 & 0 & 0 & 1 \\
\hline
\end{tabular}

Table 10: Survey of RAPD markers using Primer (OPG- 03) in bulked samples of the four species.

\begin{tabular}{|c|c|c|c|c|c|}
\hline Band No. & RAPD Marker bp & $\mathbf{1}$ & $\mathbf{2}$ & $\mathbf{3}$ & $\mathbf{4}$ \\
\hline $\mathbf{1}$ & $\mathbf{1 5 0}$ & 0 & 0 & 0 & 1 \\
\hline $\mathbf{2}$ & $\mathbf{2 0 0}$ & 1 & 1 & 1 & 0 \\
\hline $\mathbf{3}$ & $\mathbf{3 0 0}$ & 1 & 0 & 1 & 1 \\
\hline $\mathbf{4}$ & $\mathbf{3 5 0}$ & 1 & 0 & 1 & 1 \\
\hline $\mathbf{5}$ & $\mathbf{4 0 0}$ & 1 & 1 & 1 & 1 \\
\hline $\mathbf{6}$ & $\mathbf{6 0 0}$ & 1 & 0 & 1 & 1 \\
\hline $\mathbf{7}$ & $\mathbf{7 0 0}$ & 1 & 1 & 0 & 1 \\
\hline $\mathbf{8}$ & $\mathbf{7 5 0}$ & 0 & 0 & 0 & 1 \\
\hline
\end{tabular}

Table 11: Survey of RAPD markers using Primer (OPG- 07) in bulked samples of the four species.

\begin{tabular}{|c|c|c|c|c|c|}
\hline Band No. & RAPD Marker bp & $\mathbf{1}$ & $\mathbf{2}$ & $\mathbf{3}$ & $\mathbf{4}$ \\
\hline $\mathbf{1}$ & $\mathbf{1 5 0}$ & 0 & 1 & 0 & 0 \\
\hline $\mathbf{2}$ & $\mathbf{2 0 0}$ & 1 & 0 & 1 & 1 \\
\hline $\mathbf{3}$ & $\mathbf{3 2 0}$ & 0 & 1 & 1 & 1 \\
\hline $\mathbf{4}$ & $\mathbf{3 5 0}$ & 0 & 1 & 1 & 1 \\
\hline $\mathbf{5}$ & $\mathbf{3 8 0}$ & 0 & 0 & 1 & 0 \\
\hline $\mathbf{6}$ & $\mathbf{3 9 0}$ & 0 & 1 & 1 & 1 \\
\hline $\mathbf{7}$ & $\mathbf{4 5 0}$ & 1 & 0 & 1 & 1 \\
\hline $\mathbf{8}$ & $\mathbf{4 8 0}$ & 1 & 0 & 1 & 0 \\
\hline $\mathbf{9}$ & $\mathbf{5 0 0}$ & 0 & 1 & 0 & 1 \\
\hline $\mathbf{1 0}$ & $\mathbf{5 5 0}$ & 0 & 1 & 0 & 1 \\
\hline $\mathbf{1 1}$ & $\mathbf{7 5 0}$ & 0 & 1 & 1 & 1 \\
\hline $\mathbf{1 2}$ & $\mathbf{8 0 0}$ & 0 & 1 & 1 & 1 \\
\hline $\mathbf{1 3}$ & $\mathbf{1 0 0 0}$ & 1 & 1 & 1 & 1 \\
\hline $\mathbf{1 4}$ & $\mathbf{1 2 0 0}$ & 0 & 1 & 0 & 0 \\
\hline
\end{tabular}

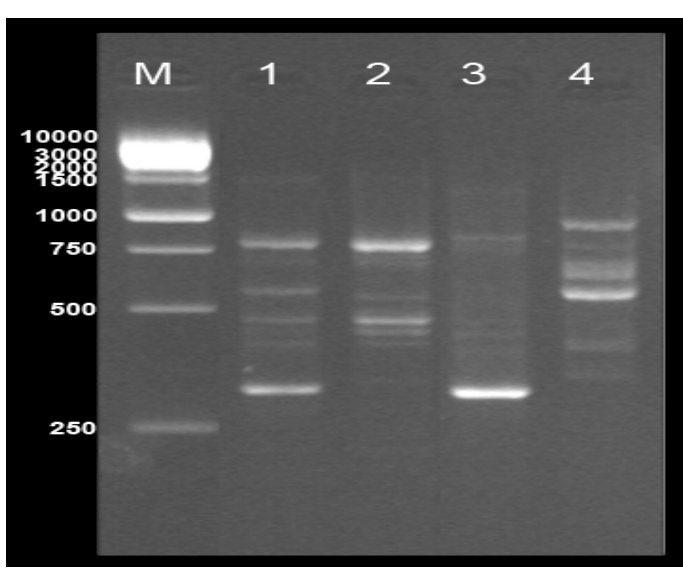

Fig. 8: Agarose-gel electrophoresis of RAPD products generated with Primer OPE-05 with the four species.

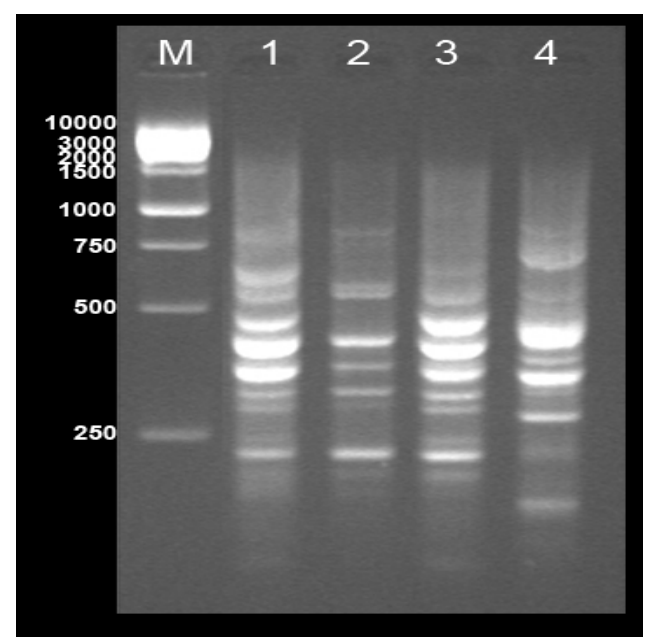

Fig. 9: Agarose-gel electrophoresis of RAPD products generated with Primer OPG-03 with the four species.

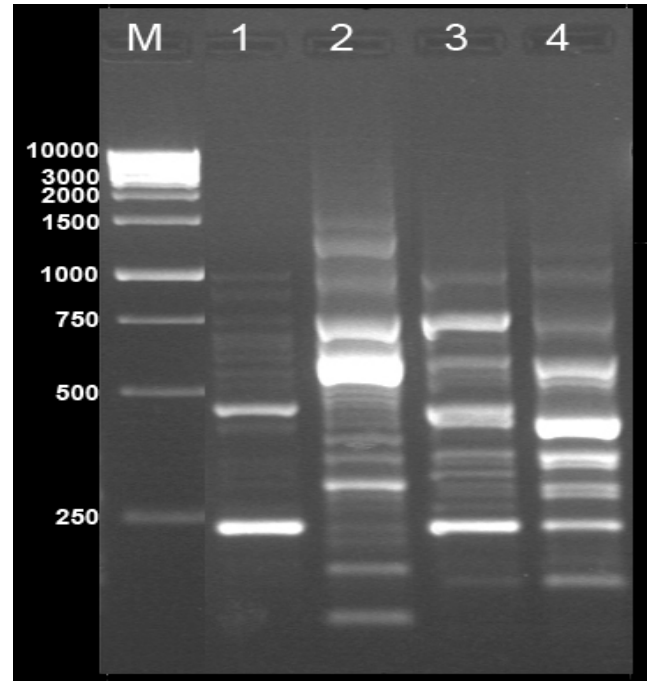

Fig. 10: Agarose-gel electrophoresis of RAPD products generated with Primer OPG-07 with the four species. 
Primer OPG-13 generated 7 DNA fragments ranged in size between 200 and 650 bp (Table 12 \& Fig. 11) (71 \%) of these fragments (5 fragments) were polymorphic between the four species of Cephalopholis, primer OPG-19 generated 7 fragments between 150 and $850 \mathrm{bp}$ (Table 13 \& Fig. 12), OPH-13 gave 9 fragments from 150 to $680 \mathrm{bp}$ (Table 14 \& Fig. 13), (same primer OPH-13 gave 48 bands, 9 of them polymorphic in Tenualosa ilisha Ham of the Clupeidae family (Shifat et al., 2003), OPM-11 gave 13 fragments in the four species of Cephalopholis ranged in size between 120 and 580 bp (Table 15 \& Fig. 14) and primer OPM-12 generated 10 fragments from 150 to $600 \mathrm{bp}$ (Table 16 \& Fig. 15).

Table 12: Survey of RAPD markers using Primer (OPG-13) in bulked samples of the four species.

\begin{tabular}{|c|c|c|c|c|c|}
\hline Band No. & RAPD Marker bp & $\mathbf{1}$ & $\mathbf{2}$ & $\mathbf{3}$ & $\mathbf{4}$ \\
\hline $\mathbf{1}$ & $\mathbf{2 0 0}$ & 1 & 1 & 0 & 1 \\
\hline $\mathbf{2}$ & $\mathbf{2 5 0}$ & 1 & 0 & 1 & 1 \\
\hline $\mathbf{3}$ & $\mathbf{3 2 0}$ & 1 & 1 & 1 & 1 \\
\hline $\mathbf{4}$ & $\mathbf{3 8 0}$ & 1 & 1 & 1 & 1 \\
\hline $\mathbf{5}$ & $\mathbf{4 0 0}$ & 1 & 1 & 1 & 0 \\
\hline $\mathbf{6}$ & $\mathbf{5 0 0}$ & 1 & 0 & 0 & 0 \\
\hline $\mathbf{7}$ & $\mathbf{6 5 0}$ & 1 & 1 & 1 & 0 \\
\hline
\end{tabular}

Table 13: Survey of RAPD markers using Primer (OPG- 19) in bulked samples of the four species.

\begin{tabular}{|c|c|c|c|c|c|}
\hline Band No. & RAPD Marker bp & $\mathbf{1}$ & $\mathbf{2}$ & $\mathbf{3}$ & $\mathbf{4}$ \\
\hline $\mathbf{1}$ & $\mathbf{1 5 0}$ & 0 & 1 & 1 & 1 \\
\hline $\mathbf{2}$ & $\mathbf{2 5 0}$ & 1 & 0 & 1 & 1 \\
\hline $\mathbf{3}$ & $\mathbf{3 0 0}$ & 1 & 0 & 1 & 0 \\
\hline $\mathbf{4}$ & $\mathbf{3 5 0}$ & 1 & 1 & 1 & 1 \\
\hline $\mathbf{5}$ & $\mathbf{4 5 0}$ & 1 & 0 & 0 & 1 \\
\hline $\mathbf{6}$ & $\mathbf{5 0 0}$ & 1 & 0 & 0 & 1 \\
\hline 7 & $\mathbf{8 5 0}$ & 1 & 0 & 0 & 1 \\
\hline
\end{tabular}

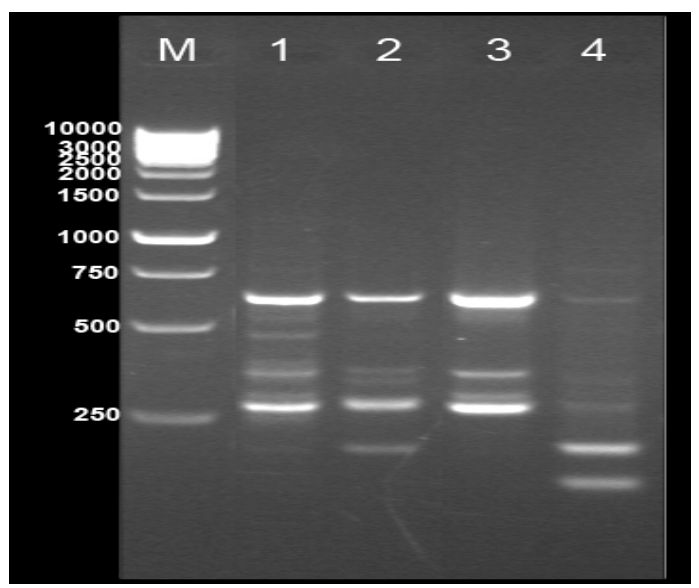

Fig. 11: Agarose-gel electrophoresis of RAPD products generated with Primer OPG-13 with the four species.

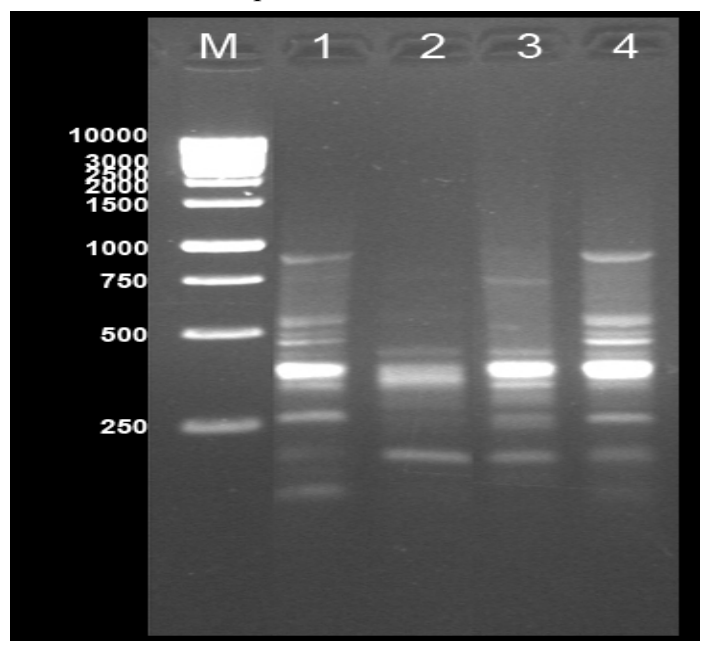

Fig. 12: Agarose-gel electrophoresis of RAPD products generated with Primer OPG-19 with the four species. 
Table 14: Survey of RAPD markers using Primer (OPH-13) in bulked samples of the four species.

\begin{tabular}{|c|c|c|c|c|c|}
\hline Band No. & RAPD Marker bp & $\mathbf{1}$ & $\mathbf{2}$ & $\mathbf{3}$ & $\mathbf{4}$ \\
\hline $\mathbf{1}$ & $\mathbf{1 5 0}$ & 1 & 1 & 0 & 0 \\
\hline $\mathbf{2}$ & $\mathbf{2 0 0}$ & 1 & 0 & 0 & 0 \\
\hline $\mathbf{3}$ & $\mathbf{2 2 0}$ & 1 & 1 & 1 & 1 \\
\hline $\mathbf{4}$ & $\mathbf{2 5 0}$ & 0 & 1 & 0 & 0 \\
\hline $\mathbf{5}$ & $\mathbf{3 0 0}$ & 0 & 1 & 1 & 1 \\
\hline $\mathbf{6}$ & $\mathbf{4 0 0}$ & 0 & 0 & 1 & 1 \\
\hline $\mathbf{7}$ & $\mathbf{4 2 0}$ & 1 & 1 & 0 & 0 \\
\hline $\mathbf{8}$ & $\mathbf{5 0 0}$ & 1 & 0 & 0 & 1 \\
\hline $\mathbf{9}$ & $\mathbf{6 8 0}$ & 0 & 0 & 1 & 1 \\
\hline
\end{tabular}

Table 13: Survey of RAPD markers using Primer (OPG- 19) in bulked samples of the four species.

\begin{tabular}{|c|c|c|c|c|c|}
\hline Band No. & RAPD Marker bp & $\mathbf{1}$ & $\mathbf{2}$ & $\mathbf{3}$ & $\mathbf{4}$ \\
\hline $\mathbf{1}$ & $\mathbf{1 2 0}$ & 1 & 0 & 0 & 0 \\
\hline $\mathbf{2}$ & $\mathbf{1 5 0}$ & 1 & 1 & 0 & 1 \\
\hline $\mathbf{3}$ & $\mathbf{2 0 0}$ & 0 & 0 & 0 & 1 \\
\hline $\mathbf{4}$ & $\mathbf{2 2 0}$ & 1 & 1 & 1 & 1 \\
\hline $\mathbf{5}$ & $\mathbf{2 5 0}$ & 1 & 1 & 1 & 1 \\
\hline $\mathbf{6}$ & $\mathbf{3 0 0}$ & 1 & 1 & 1 & 0 \\
\hline $\mathbf{7}$ & $\mathbf{3 5 0}$ & 1 & 0 & 0 & 0 \\
\hline $\mathbf{8}$ & $\mathbf{3 7 0}$ & 1 & 1 & 1 & 0 \\
\hline $\mathbf{9}$ & $\mathbf{4 0 0}$ & 1 & 1 & 0 & 1 \\
\hline $\mathbf{1 0}$ & $\mathbf{4 5 0}$ & 0 & 0 & 1 & 0 \\
\hline $\mathbf{1 1}$ & $\mathbf{4 8 0}$ & 1 & 1 & 1 & 1 \\
\hline $\mathbf{1 2}$ & $\mathbf{5 0 0}$ & 0 & 0 & 0 & 1 \\
\hline $\mathbf{1 3}$ & $\mathbf{5 8 0}$ & 0 & 0 & 1 & 0 \\
\hline
\end{tabular}

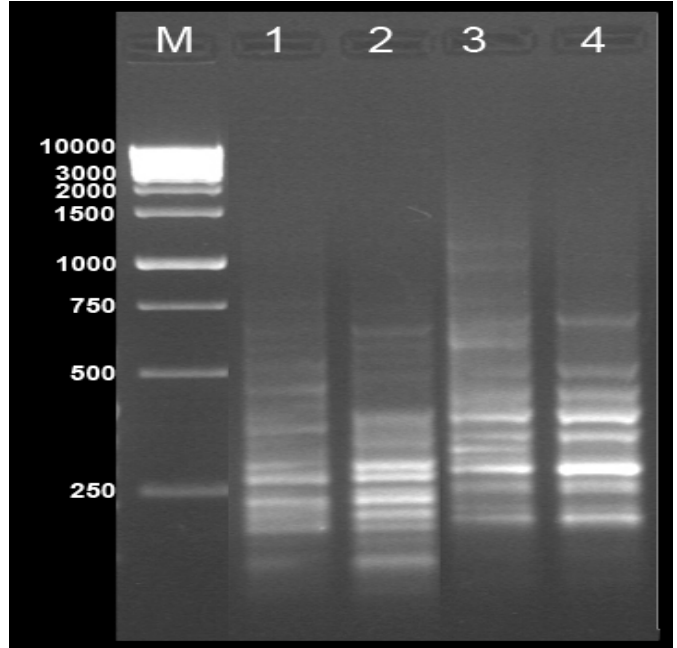

Fig. 13: Agarose-gel electrophoresis of RAPD products generated with Primer OPH-13 with the four species.

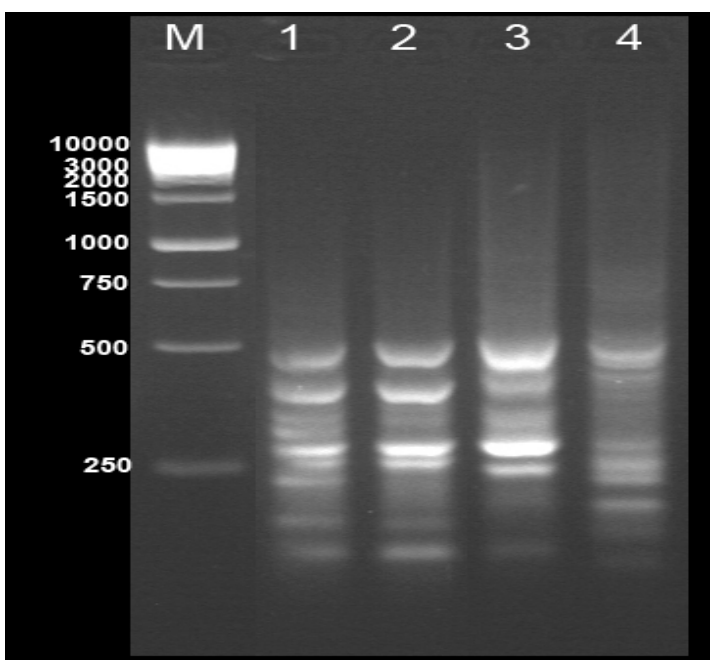

Fig. 14: Agarose-gel electrophoresis of RAPD products generated with Primer OPM-11 with the four species. 
Table 16: Survey of RAPD markers using Primer (OPM-12) in bulked samples of the four species.

\begin{tabular}{|c|c|c|c|c|c|}
\hline Band No. & RAPD Marker bp & $\mathbf{1}$ & $\mathbf{2}$ & $\mathbf{3}$ & $\mathbf{4}$ \\
\hline $\mathbf{1}$ & $\mathbf{1 5 0}$ & 0 & 1 & 1 & 0 \\
\hline $\mathbf{2}$ & $\mathbf{1 7 0}$ & 1 & 0 & 0 & 1 \\
\hline $\mathbf{3}$ & $\mathbf{2 0 0}$ & 1 & 1 & 1 & 1 \\
\hline $\mathbf{4}$ & $\mathbf{2 5 0}$ & 0 & 0 & 1 & 0 \\
\hline $\mathbf{5}$ & $\mathbf{3 0 0}$ & 1 & 1 & 1 & 1 \\
\hline $\mathbf{6}$ & $\mathbf{3 5 0}$ & 1 & 0 & 0 & 1 \\
\hline $\mathbf{7}$ & $\mathbf{4 0 0}$ & 1 & 0 & 1 & 1 \\
\hline $\mathbf{8}$ & $\mathbf{5 0 0}$ & 1 & 0 & 1 & 1 \\
\hline $\mathbf{9}$ & $\mathbf{5 5 0}$ & 1 & 0 & 1 & 1 \\
\hline $\mathbf{1 0}$ & $\mathbf{6 0 0}$ & 1 & 0 & 0 & 1 \\
\hline
\end{tabular}

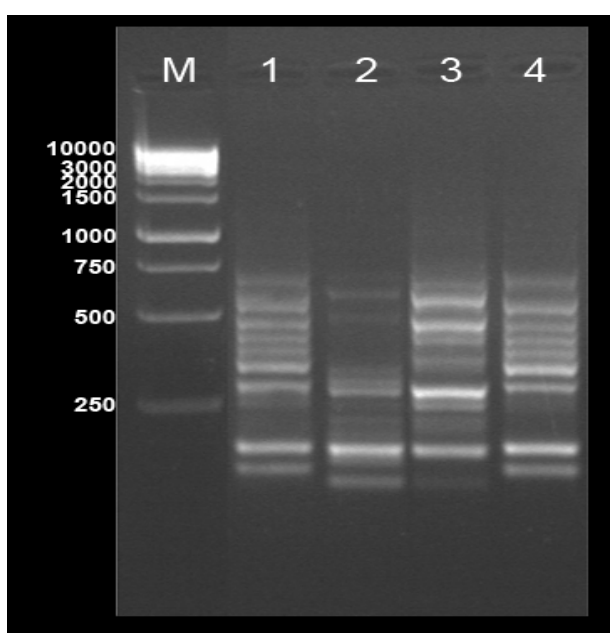

Fig. 15: Agarose-gel electrophoresis of RAPD products generated with Primer OPM-12 with the four species.

Primer OPO-09 generated 11 fragments ranged in size between 150 and $580 \mathrm{bp}$ (Table 17 \& Fig. 16), OPZ-01 9 bands from 150 to 500 bp (Table 18 \& Fig. 17), OPZ049 bands between 150 and 500 bp (Table $19 \&$ Fig. 18), OPZ-13 12 bands from 200 to $1000 \mathrm{bp}$ (Table 20 \& Fig. 19) and OPZ-19 gave 14 bands between 180 and $800 \mathrm{bp}$ (Table 21 \& Fig. 20).

Table 17: Survey of RAPD markers using Primer (OPO- 09) in bulked samples of the four species.

\begin{tabular}{|c|c|c|c|c|c|}
\hline Band No. & RAPD Marker bp & $\mathbf{1}$ & $\mathbf{2}$ & $\mathbf{3}$ & $\mathbf{4}$ \\
\hline $\mathbf{1}$ & $\mathbf{1 5 0}$ & 1 & 0 & 1 & 0 \\
\hline $\mathbf{2}$ & $\mathbf{1 7 0}$ & 1 & 0 & 1 & 1 \\
\hline $\mathbf{3}$ & $\mathbf{2 4 0}$ & 1 & 1 & 1 & 1 \\
\hline $\mathbf{4}$ & $\mathbf{2 5 0}$ & 1 & 1 & 0 & 1 \\
\hline $\mathbf{5}$ & $\mathbf{3 0 0}$ & 1 & 1 & 1 & 1 \\
\hline $\mathbf{6}$ & $\mathbf{3 5 0}$ & 0 & 1 & 1 & 1 \\
\hline $\mathbf{7}$ & $\mathbf{3 7 0}$ & 1 & 0 & 1 & 0 \\
\hline $\mathbf{8}$ & $\mathbf{4 2 0}$ & 1 & 1 & 1 & 1 \\
\hline $\mathbf{9}$ & $\mathbf{4 4 0}$ & 1 & 1 & 1 & 1 \\
\hline $\mathbf{1 0}$ & $\mathbf{4 8 0}$ & 0 & 0 & 0 & 1 \\
\hline $\mathbf{1 1}$ & $\mathbf{5 8 0}$ & 0 & 1 & 0 & 0 \\
\hline
\end{tabular}

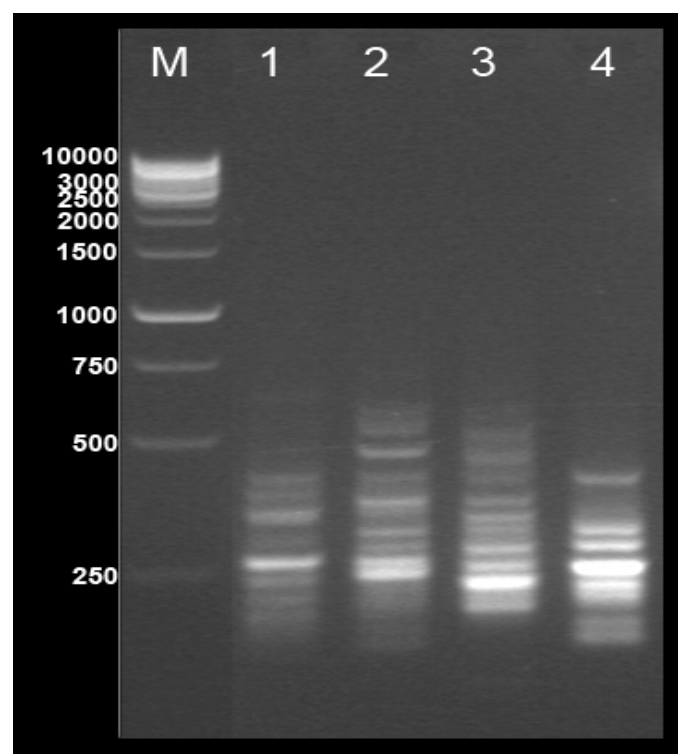

Fig. 16: Agarose-gel electrophoresis of RAPD products generated with Primer OPO-09 with the four species. 
Table 18: Survey of RAPD markers using Primer (OPZ- 01) in bulked samples of the four species.

\begin{tabular}{|c|c|c|c|c|c|}
\hline Band No. & RAPD Marker bp & $\mathbf{1}$ & $\mathbf{2}$ & $\mathbf{3}$ & $\mathbf{4}$ \\
\hline $\mathbf{1}$ & $\mathbf{1 5 0}$ & 1 & 0 & 1 & 0 \\
\hline $\mathbf{2}$ & $\mathbf{1 8 0}$ & 1 & 1 & 1 & 1 \\
\hline $\mathbf{3}$ & $\mathbf{2 4 0}$ & 1 & 1 & 1 & 1 \\
\hline $\mathbf{4}$ & $\mathbf{2 5 0}$ & 0 & 0 & 0 & 1 \\
\hline $\mathbf{5}$ & $\mathbf{3 0 0}$ & 1 & 1 & 0 & 1 \\
\hline $\mathbf{6}$ & $\mathbf{3 2 0}$ & 1 & 1 & 1 & 0 \\
\hline $\mathbf{7}$ & $\mathbf{3 5 0}$ & 1 & 1 & 1 & 1 \\
\hline $\mathbf{8}$ & $\mathbf{4 5 0}$ & 1 & 1 & 1 & 0 \\
\hline $\mathbf{9}$ & $\mathbf{5 0 0}$ & 0 & 0 & 0 & 1 \\
\hline
\end{tabular}

Table 19: Survey of RAPD markers using Primer (OPZ- 04) in bulked samples of the four species.

\begin{tabular}{|c|c|c|c|c|c|}
\hline Band No. & RAPD Marker bp & $\mathbf{1}$ & $\mathbf{2}$ & $\mathbf{3}$ & $\mathbf{4}$ \\
\hline $\mathbf{1}$ & $\mathbf{1 5 0}$ & 1 & 1 & 1 & 0 \\
\hline $\mathbf{2}$ & $\mathbf{1 8 0}$ & 1 & 1 & 1 & 1 \\
\hline $\mathbf{3}$ & $\mathbf{2 0 0}$ & 0 & 1 & 1 & 1 \\
\hline $\mathbf{4}$ & $\mathbf{2 3 0}$ & 1 & 0 & 0 & 1 \\
\hline $\mathbf{5}$ & $\mathbf{2 5 0}$ & 1 & 1 & 1 & 1 \\
\hline $\mathbf{6}$ & $\mathbf{3 2 0}$ & 1 & 0 & 1 & 1 \\
\hline $\mathbf{7}$ & $\mathbf{3 5 0}$ & 1 & 1 & 1 & 0 \\
\hline $\mathbf{8}$ & $\mathbf{4 0 0}$ & 1 & 1 & 1 & 0 \\
\hline $\mathbf{9}$ & $\mathbf{5 0 0}$ & 0 & 0 & 1 & 0 \\
\hline
\end{tabular}

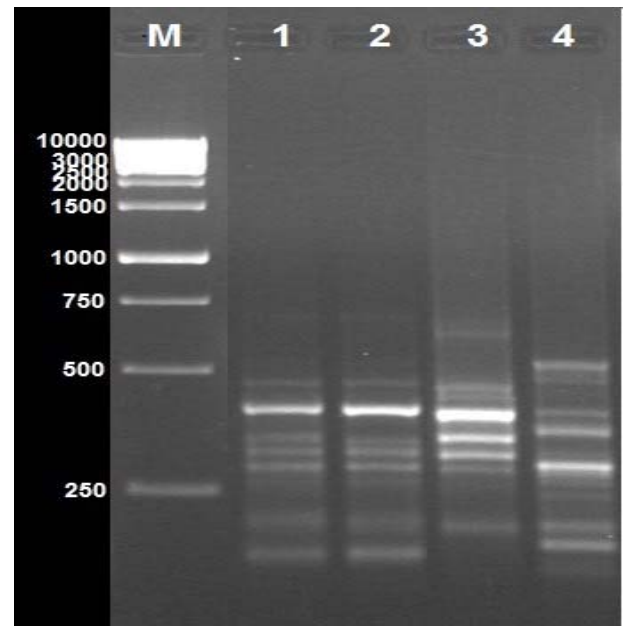

Fig. 17: Agarose-gel electrophoresis of RAPD products generated with Primer OPZ-01 with the four species.

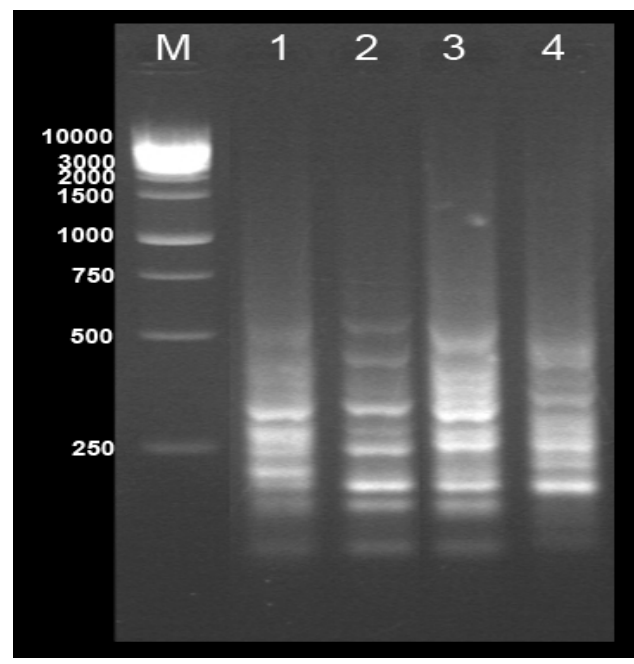

Fig. 18: Agarose-gel electrophoresis of RAPD products generated with Primer OPZ-04 with the four species. 
Table 20: Survey of RAPD markers using Primer (OPZ-13) in bulked samples of the four species.

\begin{tabular}{|c|c|c|c|c|c|}
\hline Band No. & RAPD Marker bp & $\mathbf{1}$ & $\mathbf{2}$ & $\mathbf{3}$ & $\mathbf{4}$ \\
\hline $\mathbf{1}$ & $\mathbf{2 0 0}$ & 1 & 1 & 1 & 1 \\
\hline $\mathbf{2}$ & $\mathbf{2 2 0}$ & 0 & 1 & 1 & 0 \\
\hline $\mathbf{3}$ & $\mathbf{2 8 0}$ & 1 & 1 & 0 & 0 \\
\hline $\mathbf{4}$ & $\mathbf{3 0 0}$ & 1 & 0 & 0 & 1 \\
\hline $\mathbf{5}$ & $\mathbf{3 4 0}$ & 1 & 0 & 1 & 0 \\
\hline $\mathbf{6}$ & $\mathbf{4 0 0}$ & 1 & 1 & 1 & 1 \\
\hline $\mathbf{7}$ & $\mathbf{4 2 0}$ & 1 & 1 & 0 & 1 \\
\hline $\mathbf{8}$ & $\mathbf{4 6 0}$ & 1 & 1 & 0 & 0 \\
\hline $\mathbf{9}$ & $\mathbf{5 0 0}$ & 0 & 1 & 0 & 1 \\
\hline $\mathbf{1 0}$ & $\mathbf{6 8 0}$ & 1 & 0 & 1 & 0 \\
\hline 11 & $\mathbf{7 5 0}$ & 1 & 0 & 1 & 0 \\
\hline $\mathbf{1 2}$ & $\mathbf{1 0 0 0}$ & 1 & 0 & 1 & 1 \\
\hline
\end{tabular}

Table 21: Survey of RAPD markers using Primer (OPZ-19) in bulked samples of the four species.

\begin{tabular}{|c|c|c|c|c|c|}
\hline Band No. & RAPD Marker bp & $\mathbf{1}$ & $\mathbf{2}$ & $\mathbf{3}$ & $\mathbf{4}$ \\
\hline $\mathbf{1}$ & $\mathbf{1 8 0}$ & 0 & 0 & 0 & 1 \\
\hline $\mathbf{2}$ & $\mathbf{2 0 0}$ & 1 & 1 & 1 & 0 \\
\hline $\mathbf{3}$ & $\mathbf{2 5 0}$ & 1 & 1 & 0 & 1 \\
\hline $\mathbf{4}$ & $\mathbf{2 8 0}$ & 1 & 1 & 0 & 1 \\
\hline $\mathbf{5}$ & $\mathbf{3 2 0}$ & 1 & 1 & 0 & 1 \\
\hline $\mathbf{6}$ & $\mathbf{3 8 0}$ & 1 & 1 & 1 & 1 \\
\hline $\mathbf{7}$ & $\mathbf{4 2 0}$ & 1 & 1 & 1 & 0 \\
\hline $\mathbf{8}$ & $\mathbf{4 6 0}$ & 1 & 1 & 0 & 0 \\
\hline $\mathbf{9}$ & $\mathbf{4 8 0}$ & 1 & 1 & 1 & 0 \\
\hline $\mathbf{1 0}$ & $\mathbf{5 0 0}$ & 1 & 1 & 1 & 1 \\
\hline $\mathbf{1 1}$ & $\mathbf{5 8 0}$ & 1 & 1 & 1 & 1 \\
\hline $\mathbf{1 2}$ & $\mathbf{6 0 0}$ & 0 & 0 & 1 & 1 \\
\hline $\mathbf{1 3}$ & $\mathbf{7 5 0}$ & 0 & 0 & 1 & 0 \\
\hline $\mathbf{1 4}$ & $\mathbf{8 0 0}$ & 0 & 1 & 0 & 0 \\
\hline
\end{tabular}

The number of bands was variable in each species. Cephalopholis argus was the species that produced the greatest number of bands (141), and Cephalopholis sexmaculata was the lowest (111). In the other two species, C. oligosticta and C. hemistiktos, the total number of bands was 138 and 125 respectively. Generally, a total of 515 DNA bands were generated by all primers in all specimens, out of these DNA bands $39(19.02 \%)$ were conserved among all specimens while 166 bands were polymorphic with percentage $81 \%$ of all the twenty tested primers as shown in Table (22).

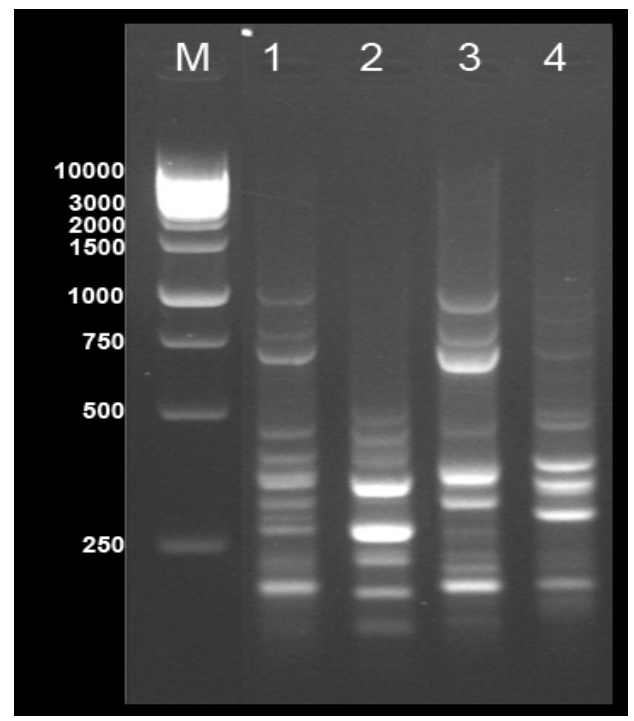

Fig. 19: Agarose-gel electrophoresis of RAPD products generated with Primer OPZ-13 with the four species.

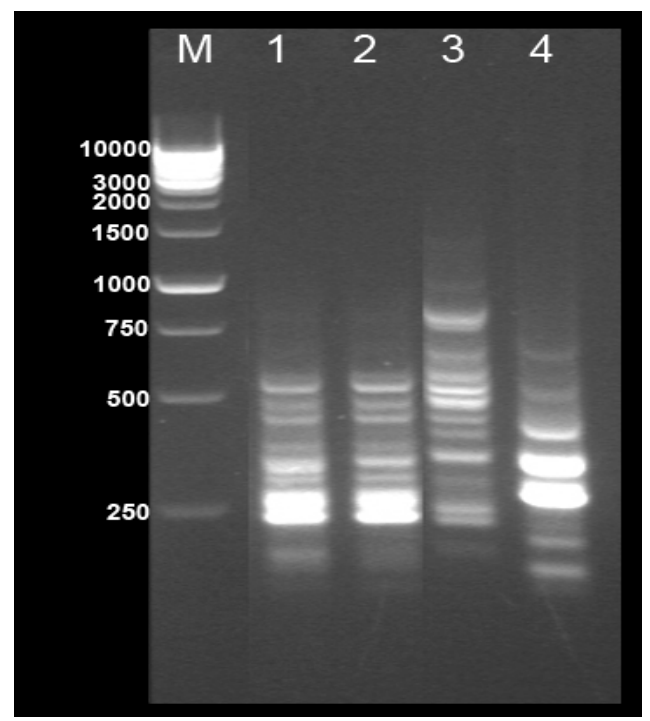

Fig. 20: Agarose-gel electrophoresis of RAPD products generated with Primer OPZ-19 with the four species. 
Table 22: Number of amplified and polymorphic DNA - fragments in the four speciemens.

\begin{tabular}{|c|c|c|c|c|c|c|c|c|}
\hline \multirow{3}{*}{ No. } & \multirow{3}{*}{ Primer code } & \multirow{3}{*}{$\begin{array}{l}\text { Total of } \\
\text { amplified } \\
\text { bands }\end{array}$} & \multirow{2}{*}{\multicolumn{4}{|c|}{ No. of amplified bands }} & \multirow{3}{*}{$\begin{array}{l}\text { No. of } \\
\text { common } \\
\text { bands }\end{array}$} & \multirow{3}{*}{$\begin{array}{l}\text { No. of } \\
\text { polymorphic } \\
\text { bands }\end{array}$} \\
\hline & & & & & & & & \\
\hline & & & 1 & 2 & 3 & 4 & & \\
\hline 1 & OPA-04 & 12 & 4 & 5 & 10 & 9 & 1 & 11 \\
\hline 2 & OPA-06 & 10 & 8 & 4 & 7 & 5 & 1 & 9 \\
\hline 3 & OPA-11 & 12 & 4 & 8 & 10 & 11 & 4 & 8 \\
\hline 4 & OPA-17 & 14 & 12 & 9 & 9 & 11 & 6 & 8 \\
\hline 5 & OPB-14 & 9 & 2 & 7 & 3 & 7 & 1 & 8 \\
\hline 6 & OPD-01 & 10 & 8 & 1 & 1 & 6 & 0 & 10 \\
\hline 7 & OPD-14 & 9 & 8 & 1 & 5 & 8 & 1 & 8 \\
\hline 8 & OPE-05 & 6 & 5 & 4 & 1 & 4 & 0 & 6 \\
\hline 9 & OPG-03 & 8 & 6 & 3 & 5 & 7 & 1 & 7 \\
\hline 10 & OPG-07 & 14 & 4 & 10 & 10 & 10 & 1 & 13 \\
\hline 11 & OPG-13 & 7 & 7 & 5 & 5 & 4 & 2 & 5 \\
\hline 12 & OPG-19 & 7 & 6 & 2 & 4 & 6 & 1 & 6 \\
\hline 13 & OPH-13 & 9 & 5 & 5 & 4 & 5 & 1 & 8 \\
\hline 14 & OPM-11 & 13 & 9 & 7 & 7 & 7 & 3 & 10 \\
\hline 15 & OPM-12 & 10 & 8 & 3 & 7 & 8 & 2 & 8 \\
\hline 16 & OPO-09 & 11 & 8 & 7 & 8 & 8 & 4 & 7 \\
\hline 17 & OPZ-01 & 9 & 7 & 6 & 6 & 6 & 3 & 6 \\
\hline 18 & OPZ-04 & 9 & 7 & 6 & 8 & 5 & 2 & 7 \\
\hline 19 & OPZ-13 & 12 & 10 & 7 & 7 & 6 & 2 & 10 \\
\hline 20 & OPZ-19 & 14 & 10 & 11 & 8 & 8 & 3 & 11 \\
\hline \multicolumn{2}{|c|}{ Total } & 205 & 138 & 111 & 125 & 141 & 39 & 166 \\
\hline
\end{tabular}

Data of presence/absence of DNA fragments of the four species were used to calculate the genetic similarity. Based on the calculated genetic similarity presented in Table (23) and dendrogram Figure (21), an estimation of the genetic relationship between the above species was concluded where the highest genetic similarity value $67.1 \%$ was observed between C. hemistiktos and C. argus, while the lowest value $59.8 \%$ was found between $C$. oligosticta and $C$. sexmaculata. The UPGMA dendrogram shows three clusters; (A) contained Cephalopholis hemistiktos and $C$. argus, cluster (B) contained C. oligosticta and (C. hemistiktos and C. argus) and cluster (C) contained C. sexmaculata and (C. oligosticta, C. hemistiktos and C. argus).

Table 23: Similarity matrix UPGMA Jaccard's Coefficient

\begin{tabular}{|c|c|c|c|c|}
\hline & $\begin{array}{c}\text { Cephalopholis } \\
\text { oligosticta }\end{array}$ & $\begin{array}{c}\text { Cephalopholis } \\
\text { sexmaculata }\end{array}$ & $\begin{array}{c}\text { Cephalopholis } \\
\text { hemistiktos }\end{array}$ & $\begin{array}{c}\text { Cephalopholis } \\
\text { argus }\end{array}$ \\
\hline $\begin{array}{c}\text { Cephalopholis } \\
\text { oligosticta }\end{array}$ & 100 & & & \\
\hline $\begin{array}{c}\text { Cephalopholis } \\
\text { sexmaculata }\end{array}$ & 59.8 & 100 & & \\
\hline $\begin{array}{c}\text { Cephalopholis } \\
\text { hemistiktos }\end{array}$ & 65 & 62.4 & 100 & \\
\hline $\begin{array}{c}\text { Cephalopholis } \\
\text { argus }\end{array}$ & 66.7 & 62.2 & 67.1 & 100 \\
\hline
\end{tabular}




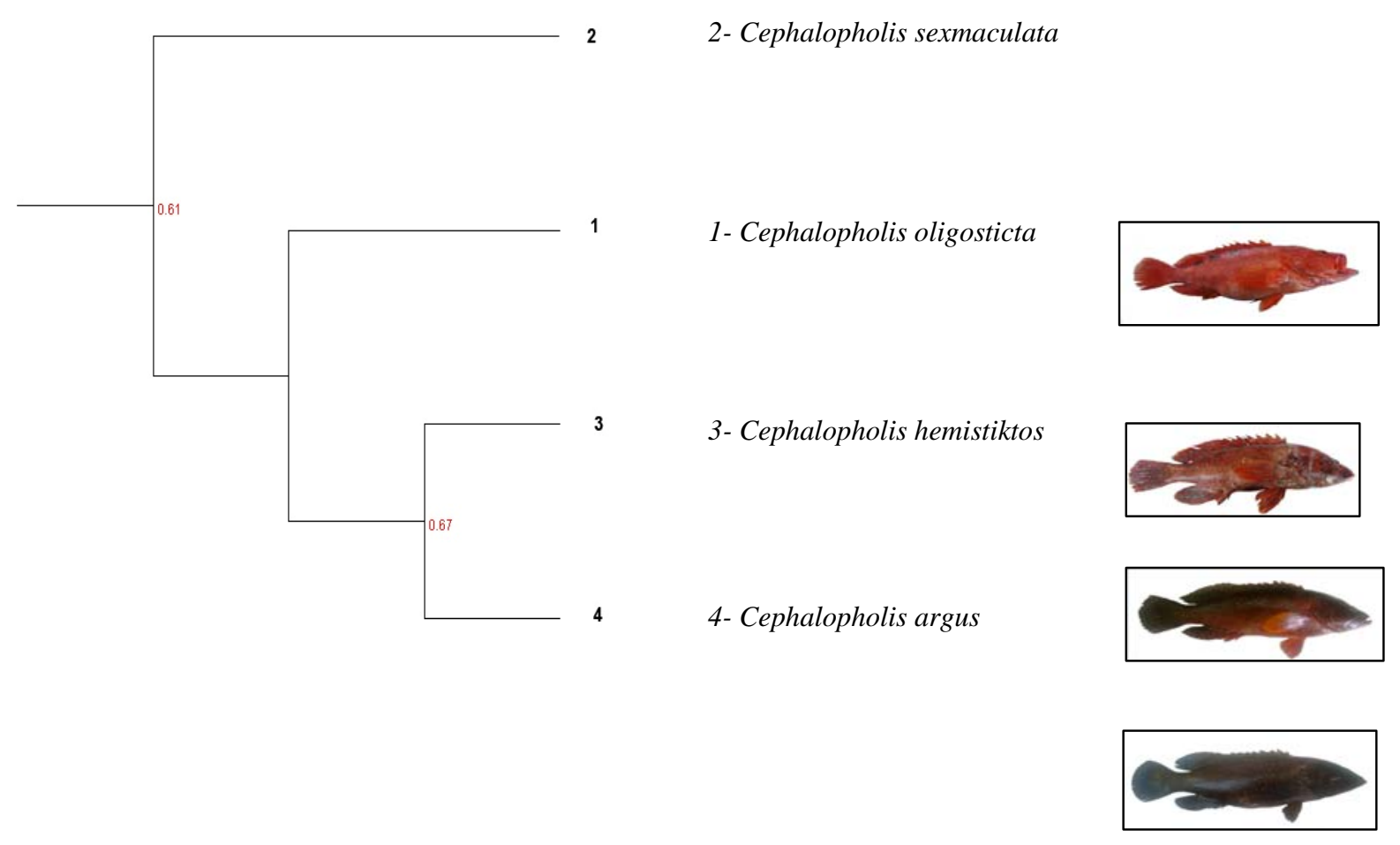

Fig. 21: Dendogram demonstrating the relationship between the four species, based on data recoreded from polymorphism of RAPD markers.

Based on the previous results, it was confirmed that RAPDs reveal similar patterns of genetic diversity when compared with other marker types and can be performed more rapidly than most other methods. Moreover, it can provide vital information for the development of genetic sampling, conservation and improvement strategies. RAPD method has been initially used to detect polymorphism in genetic mapping, taxonomy, phylogenetic studies (Chalmers et al., 1994; Morell et al., 1995) and later in genotoxicity and carcinogenesis studies (Atienzer and Jha, 2006).

\section{REFERENCES}

Affonso, P. and Galetti Jr., P. M. (2007). Genetic diversity of three ornamental reef fishes (Families Pomacanthidae and Chaetodontidae) from the Brazilian coast. Braz. J. Biol., 67(4): 925-933.

Atienzar, F. A. and Jha, A. N. (2006). The random amplified polymorphic DNA (RAPD) assay and related techniques applied to genotoxicity and carcinogenesis studies: A critical review. Mutan. Res., 613 (2-3). 76-102.

Bardakci, F. and Skibinski, D. O. F. (1994): Application of the RAPD technique in tilapia fish: species and subspecies identification. Heredity, The Genetical Society of Great Britain, 73: 117-123.

Chalmers, K. J.; Newton, A. C.; Waugh, R. and Powell, W. (1994). Evaluation of the extent of genetic variation in mahoganies (Meliaceae) using RAPD markers. Theor. Genet. 89:504-508. 
Dinesh, KR.; Lin, T M.; Chua, KL.; Chan, WK. and Phang, VP. (1993). RAPD analysis: an efficient method of DNA fingerprinting in fishes. Zool. Sci., vol. 10(5):849-854.

El-Alfy, S. H.; Abdelmordy, M. and Salama, M. S. (2009). Genetic variation among Nile Tilapiine fishes (Perciformes: Cichlidae) assessed by Random Amplified Polymorphic DNA (RAPD) analysis. Res. J. Cell and Mol. Biol., 3(1): 63-70.

Imtiaz, A.; Ahmed, A.; Babar, M.; Riaz, M.; Akhtar, N.; Arshad, M. and Khaliq, I. (2011). Genetic diversity of Pakistani common myna (Acridotheres tristis) revealed by RAPD-PCR. African J. of Biotechnology, 10(40): 7751-7755.

Mjolnerod, I. B.; Refseth, U. H.; Karlsen, E.; Batslad, T.; Jakobsen, K. S. and Hindar, K. (1997). Genetic differences between two wild and one farmed population of atlantic salmon (Salmosalar) revealed by three classes of genetic markers. Hereditas, 127: 239-248.

Morell, M. K.; Peakall, R.; Appels, R.; Preston, L. R. and Lloyd, H. L. (1995). Genome mapping in Pinuspinaster (Maritime pine) using RAPD and proline marker. Heredity, 74: 661-668.

Naish, K. A.; Warren, M.; Bardakci, F.; Skibinski, D. O. F.; Carvalho, G. R. and Mair, G. C. (1995). Multilocus DNA fingerprinting and RAPD reveal similar genetic relationships between strains of Oreochromis niloticus (Pisces: Cichlidae). Molecular Ecology, 4: 271-274.

Norris, A. T.; Bradley, D. G. and Cunningham, E. P. (1999). Microsatellite genetic variation between and within farmed and wild Atlantic salmon (Salmosalar) populations. Aquaculture, 180: 247-264.

Okumus, I. and Çiftci, Y. (2003). Fish population genetics and molecular markers: IImolecular markers and their applications in fisheries and aquaculture. Turkish $\mathrm{j}$. of fisheries and aquatic sciences, 3: 51-79.

Park, L. K. and Moran, P. (1994): Development in molecular- genetic techniques in fisheries, Rev. Fish. Biol., 4: 272-299.

Saad, Y. M.; Abu Zinadah, O. A. H.; El-Domyati, F. M. and Sabir, J. M. (2012). Analysis of Genetic signature for some Plectropomus species based on some dominant DNA markers, Life science j, 9 (4).

Seleem, S. H. and Ali T. G. (2008). Application of RAPD-PCR in taxonomy of certain freshwater bivalves of genus Caelatura. Global J. of Molecular Sciences, 3 (1): 27-31.

Shifat, R.; Begum, A. and Khan, H. (2003). Use of RAPD fingerprinting for discriminating two populations of Hilsa shad (Tenualosailisha Ham.) from Inland rivers of Bangladesh: j. of biochemistry and molecular biology, 36 (5): 462-467.

Sneath, P. H. A. and Sokal, R. R. (1973). Numerical taxonomy; the principles and practice of numerical classification. San Francisco, W. H. Freeman and compay, Stony Brook, N, USA. ISBN 0-7167-0697-0.

Wasko, A. P.; Martins, C.; Oliverira, C.; Senhorini, J. A. and Foresti, F. (2004b). Genetics monitoring of the Amazonian fish matrinchã (Brycon cephalus) using RAPD markers: insight into supportive breeding and conservation programmes. J. Appl. Ichthyol., 20 (1): 48-52.

Welsh, J. and McCelland, M. (1990). Fingerprinting genomes using PCR with arbitrary primers. Nucleic Acid Res. 18: 7213-7218.

Williams, J. G.; Kubelik, A. R.; Livak, K. J.; Rafalski, J. A. and Tingey, S. V. (1990). DNA polymorphisms amplified by arbitrary primers are useful as genetic markers. Nucleic Acid Res., 18: 6531-6535. 


$$
\begin{aligned}
& \text { ARABIC SUMMARY } \\
& \text { دراسات وراثية علي ع أنواع من اسماك الشعاب المرجانية من جنس السفالوفوليس: عائلة سيرانيدي } \\
& \text { بالبحر الأحمر البر }
\end{aligned}
$$

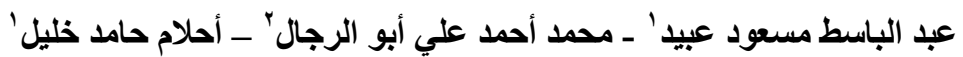

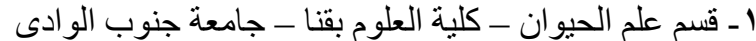

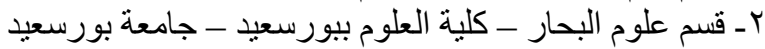

تمت در اسـة الفروق الـور اثية بين ؛ انواع تنتمسي الي جنس (Cephalopholis) و هم سيفالوفوليس

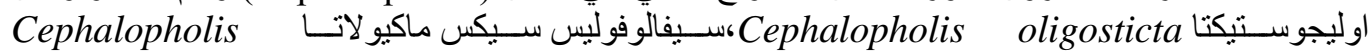
sexmaculata

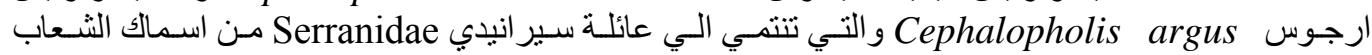
المرجانية بالبحر الاحمر من خلال : أــ تحديد بعض مقاطع الحمض الحمض النووى الدى اوكسى ريبوز (د.ن.أ) باستخدام تفاعل سلسلة البلمرة

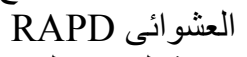

$$
\begin{aligned}
& \text { بـ دراسة الفروق الجزيئية بين هذه الانواع من خلال استخدام عشرين بادئ بطول عشر نيكليوتيدات. }
\end{aligned}
$$

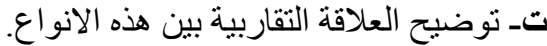

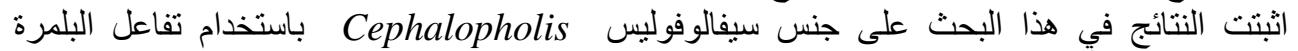

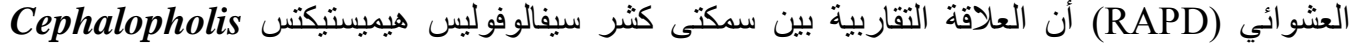
hemistiktos الاصغر بين سمكتى كثر سيفالوفوليس اوليجوستيكتا Cephalopholis oligosticta وكثر سكس ماكيو لاتا

Cephalopholis Cephalopholis sexmaculata

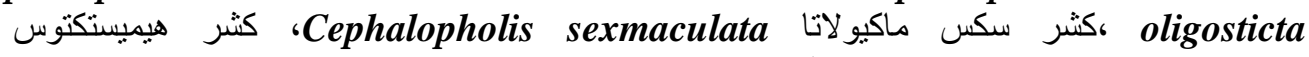
\% Cephalopholis hemistiktos

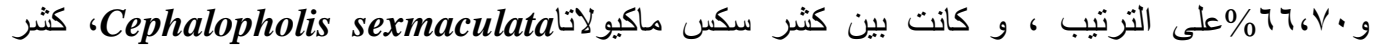

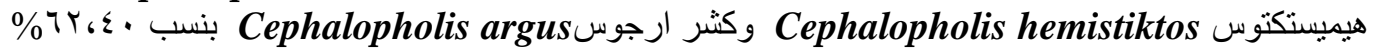

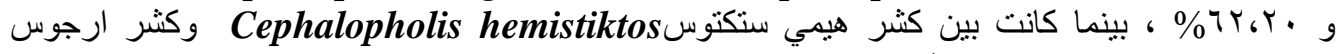
\% Cephalopholis argus

ومن النتائج السابقة يتبين لنا أن استخدام التقنيات الحديثة كتفاعل سلسلة البلمرة العشوائى يساهم كثير أ في معرفة العلاقات الور اثية بين الكائنات الحية ومدي التقارب و التباعد فيما بينها. 